\title{
Improved methodology for assaying brassinosteroids in plant tissues using magnetic hydrophilic material for both extraction and derivatization
}

Jun Ding ${ }^{1,2+}$, Jian-Hong $\mathrm{Wu}^{3+}$, Jiu-Feng Liu' ${ }^{1}$, Bi-Feng Yuan ${ }^{1}$ and Yu-Qi Feng ${ }^{1 *}$

\begin{abstract}
Background: Brassinosteriods (BRs) are a group of important phytohormones that have major effects on plant growth and development. To fully elucidate the function of BRs, a sensitive BR assay is required. However, most of the previously reported methods are tedious and time-consuming due to multiple pretreatment steps. Therefore, it is of great significance to develop a method to increase the throughput and detection sensitivity of BR analysis.

Results: We established a novel analytical method of BRs based on magnetic solid phase extraction (MSPE) combined with in situ derivatization (ISD). $\mathrm{TiO}_{2}$-coated magnetic hollow mesoporous silica spere $\left(\mathrm{TiO}_{2} / \mathrm{MHMSS}\right.$ ) was served as a double identity- a microextraction sorbent and "microreactor" for the capture and derivatization of BRs in sequence. BRs were first extracted onto $\mathrm{TiO}_{2} / \mathrm{MHMSS}$ through hydrophilic interaction. The BR-adsorbed $\mathrm{TiO}_{2} / \mathrm{MHMSS}$ was then employed as a "microreactor" for the derivatization of BRs with 4-(N,N-dimethyamino)phenylboronic acid (DMAPBA). The MSPE-ISD method was simple and fast, which could be accomplished within 10 min. Furthermore, the derivatives of BRs showed better MS response because they were incorporated with tertiary amino groups. Uniquely, endogenous BRs were detected in only $100 \mathrm{mg}$ fresh weight plant tissue.

Conclusion: Our proposed MSPE-ISD method for the determination of endogenous BRs is rapid and sensitive. It can be applied to the analysis of endogenous BRs in 100 mg fresh plant tissue (Brassica napus L. (B. napus L)). The proposed strategy for plant sample preparation may be extended to develop analytical methods for determination of a wide range of analytes with poor MS response in other complex sample matrices.
\end{abstract}

Keyword: Brassinosteroid, Magnetic solid phase extraction, In situ derivatization, Hydrophilic interaction, Liquid chromatography-mass spectrometry

\section{Background}

Brassinosteroids (BRs), a class of polyhydroxy steroid phytohormones, play critical roles in the growth and development of plants, including the germination of seeds, rhizogenesis, flowering, senescence, photomorphogenesis etc. [1,2]. Extensive studies also suggest that BRs can synergize with other phytohormones to function in the processes of reproduction, embryogenesis, hypocotal

\footnotetext{
* Correspondence: yqfeng@whu.edu.cn

${ }^{\dagger}$ Equal contributors

'Key Laboratory of Analytical Chemistry for Biology and Medicine (Ministry of Education), Department of Chemistry, Wuhan University, Wuhan 430072,

China

Full list of author information is available at the end of the article
}

elongation and so on [3-5]. The investigations of BR functions rely heavily on monitoring of the temporal and spatial variation of the BR concentrations. Therefore, an effective BR analytical method is necessary.

In recent years, the technological breakthroughs in instrumentation have improved the selectivity and sensitivity of analytical methods with the advent of high-performance liquid chromatography-tandem mass spectrometry (HPLCMS/MS) [6]. However, for the analysis of plant samples, the compromised sensitivity is frequently caused by the signal suppression from complex sample matrix during mass spectrometry (MS) analysis. Moreover, the trace amounts of BRs in complex plant matrixes and their 
inherently low MS response makes reliable qualitative and quantitative analysis of BRs challenging. The current pretreatment methods of BRs to remove the sample matrix required the combination of two or more sample preparation processes, including SPE [7,8], LLE [9], MSPE [10] etc. Besides, BRs lack ionization groups, thus the MS responses of BRs are far from satisfaction. To improve MS responses of BRs, a pre-column derivatization process was employed to incorporate ionized moieties into BRs before LC-MS analysis [7,11]. Obviously, the multiple sample preparation processes with the following derivatization procedure made BR analysis labor-consuming and timeconsuming. Therefore, it is essential to develop a fast and sensitive BR assay.

In situ derivatization (ISD) is a relatively new technique, which can couple with multiple sample preparation methods to simplify the connection of the extraction and derivatization [12,13]. So far, single-drop microextraction (SDME) [14,15], solid-phase extraction (SPE) [16,17], hollow fiber liquid-liquid-liquid extraction (HF-LLLME) [18,19], polymer monolith microextraction (PMME) [20], solid phase microextraction (SPME) [21,22] and stir bar sorptive extraction (SBSE) [23], have effectively combined with ISD for the analysis of a variety of compounds. Herein, the extraction media served as a double identity-an extractant and microreactor. After analytes were loaded onto the extraction media, the chemical derivatization reaction can occur directly on the surface of the sorbents by adding derivatization reagent. In the process, a redundant desorption/re-dissolution step was prevented and the errors associated with the multistep sample preparation process were reduced. Most importantly, the enrichment of target analytes in the extractant would benefit the fast derivatization reaction due to the local relatively high concentration. Despite of the advantages of ISD, considerable pretreatment time was still required to achieve satisfactory extraction efficiency due to the inherent limitation of the current extraction methods themselves.

Magnetic solid phase extraction (MSPE), a new mode of extraction technique based on magnetic or magnetizable nanoparticles, has been widely used in sample preparation in recent years [24-27]. The sorbents can be dispersed uniformly in sample solution by vortex, instead of being packed into the SPE cartridge. Moreover, magnetic sorbents can be readily agglomerated and re-dispersed in a sample solution by the application and removal of an external magnetic field, which makes the phase separation very convenient. From the view of mass transfer, the dispersive extraction mode also provides a large contact area between the extractant phase and sample solution, which is favorable for the mass transfer of analytes and therefore results in shorter extraction time [28]. In virtue of these properties, MSPE coupled with
ISD is a promising technique for the fast and sensitive pretreatment of BRs.

BRs contain multiple polyhydroxy groups and thus exhibit hydrophilic property. In light of this property, hydrophilic magnetic materials were chosen as sorbents, and a fast and convenient MSPE-ISD method based on hydrophilic interaction was developed for the determination of endogenous BRs in plant tissues. By employing hydrophilic magnetic material as both a microextraction sorbent and "microreactor", the MSPE-ISD method integrates extraction and derivatization together, which largely simplifies the analytical process. First, BRs were extracted onto the surface of a magnetic sorbent through hydrophilic interaction in the acetonitrile extract of the plant sample; in the meantime, hydrophobic interferents from the extract were removed. Subsequently, magnetic sorbents served as a "microreactor", where the captured BRs were rapidly and efficiently derivatized with 4-dimethylphenyl boronic acid (DMPBA). The BR derivatives could be desorbed from the sorbents with water as the desorption solvent for further UPLC-ESI-MS/MS analysis. The proposed MSPE-ISD procedure could be accomplished within $10 \mathrm{~min}$, and endogenous BRs could be detected in $100 \mathrm{mg}$ fresh weight plant tissues.

\section{Results and discussion}

\section{Optimization of MSPE-ISD}

The proposed MSPE-ISD method for the analysis of BRs utilized hydrophilic interaction to fulfill both the extraction and ISD process. In hydrophilic interaction chromatography (HILIC), the high content of acetonitrile is normally used as the sampling solution. It was already reported that the extraction efficiencies of BRs in acetonitrile were satisfactory [29], which provides an opportunity to separate them from the hydrophobic interferents based on hydrophilic interaction. Moreover, the cis-diol groups in the BR structure can react efficiently with boronate derivatization reagent $[10,30]$. Based on these backgrounds, a series of magnetic hydrophilic materials were chosen as sorbents, and DMAPBA was selected as the derivatization reagent. Several parameters affecting the extraction and derivatization efficiencies were investigated.

We first examined the performance of different types of sorbents on the extraction of BRs. Plant extract with acetonitrile contains large amounts of interfering matrix, such as pigments and hydrophobic compounds, which may jeopardize the following in situ derivatization and UPLC-ESI-MS/MS analysis. As BRs exhibit relative hydrophilic properties due to their multiple hydroxyl groups, we selected magnetic hydrophilic sorbents $\left(\mathrm{TiO}_{2} /\right.$ MHMSS, $\mathrm{Fe}_{3} \mathrm{O}_{4}, \mathrm{Fe}_{3} \mathrm{O}_{4} @ \mathrm{mSiO}_{2}, \mathrm{Fe}_{3} \mathrm{O}_{4} / \mathrm{SiO}_{2}, \mathrm{Fe}_{3} \mathrm{O}_{4} / \mathrm{TiO}_{2}$ ) for the extraction of BRs and the removal of hydrophobic matrix and pigments in the hydrophilic solid-phase extraction mode. Comparison of the performance of these 

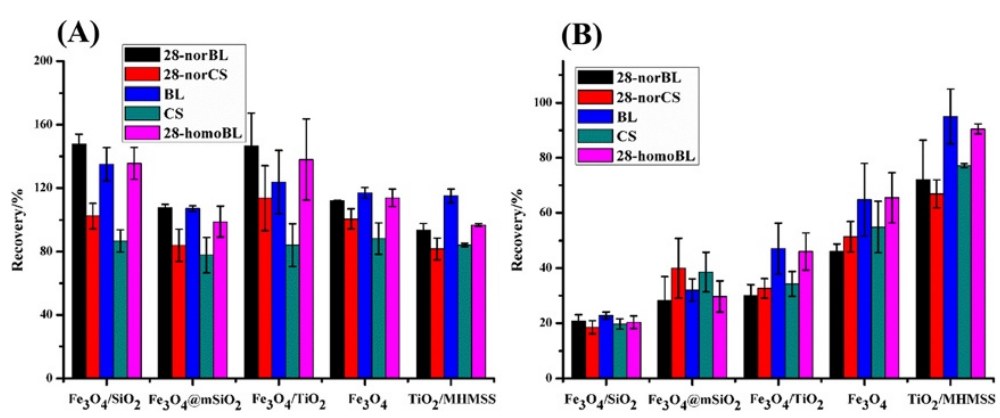

Figure 1 Effect of different magnetic sorbents on the BR recoveries in acetonitrile solution sample $(n=2)(A)$ and plant extract $(n=3)(B)$. BRs were spiked in the sampling solution at $1 \mathrm{ng} / \mathrm{mL}$ each.

hydrophilic sorbents on the extraction of BRs was conducted by examining the recoveries of BRs in acetonitrile or in plant extract. As shown in Figure 1, the five types of hydrophilic sorbents exhibited no significant difference in the recoveries of BRs spiked in acetonitrile (Figure 1A), whereas remarkable differences in the recoveries of BRs spiked in the plant extract were observed (Figure 1B). The extraction efficiencies for BRs are in the order of $\mathrm{TiO}_{2} / \mathrm{MHMSS}>\mathrm{Fe}_{3} \mathrm{O}_{4}>\mathrm{Fe}_{3} \mathrm{O}_{4} / \mathrm{TiO}_{2}>$ $\mathrm{Fe}_{3} \mathrm{O}_{4} @ \mathrm{mSiO}_{2}>\mathrm{Fe}_{3} \mathrm{O}_{4} / \mathrm{SiO}_{2}$, which may be ascribed to their differences in hydrophilic properties and the number of adsorption sites for BRs and polar compounds from the plant matrix. For BRs spiked in acetonitrile, all the five sorbent exhibited great extraction efficiencies towards BRs due to no matrix effect. However, for the plant extract, the massive matrix interferents competed with BRs for the adsorption sites, leading to low extraction efficiencies of sorbents to different extent. To assure sufficient recoveries of $\mathrm{BRs}, \mathrm{TiO}_{2} / \mathrm{MHMSS}$ was chosen as the hydrophilic sorbent for the following experiments.

We further optimized the sampling solution in MSPEISD. Volume percentages of acetonitrile in the range of 0 to $100 \%$ were investigated. As shown in Figure 2A, the highest recoveries were obtained with $100 \%$ acetonitrile; once, the proportion of water was greater than $5 \%(\mathrm{v} / \mathrm{v})$, the recoveries dropped dramatically, suggesting that the extraction efficiencies of BRs by hydrophilic sorbent of $\mathrm{TiO}_{2} /$ MHMSS are strongly dependent on the acetonitrile content (more than 95\%) in the sampling solution.

To obtain high extraction efficiencies of $\mathrm{BRs}$ by $\mathrm{TiO}_{2} /$ MHMSS, the water in the extraction solution should be removed as much as possible. However, in the process of the grinding of plant tissues in liquid nitrogen and acetonitrile extraction, water was inevitably brought into the plant extract. Here, we evaluated the dehydration strategies by either direct evaporation of plant extract and reconstitution with acetonitrile or the addition of $\mathrm{NaCl}$ and anhydrous $\mathrm{MgSO}_{4}$ into the plant extract. As shown in Figure 2B, a better dehydration effect was obtained by direct evaporation of plant extract and reconstitution with acetonitrile. Hence, the plant extract was evaporated under a mild nitrogen atmosphere and then re-dissolved in acetonitrile for the following experiments.

Because the plant extract was very complex, DMAPBA would also react with cis-diol-containing interferents in the plant extract. Therefore, to ensure high derivatization efficiency, the DMAPBA amount was investigated in both acetonitrile solution spiked with BR standards and plant extract spiked with BR standards (1 ng for each) (Figure 3). In acetonitrile, the peak areas of the BR derivatives dropped as the molar ratios increased (Figure 3A), whereas in the plant extract, the maximal peak areas
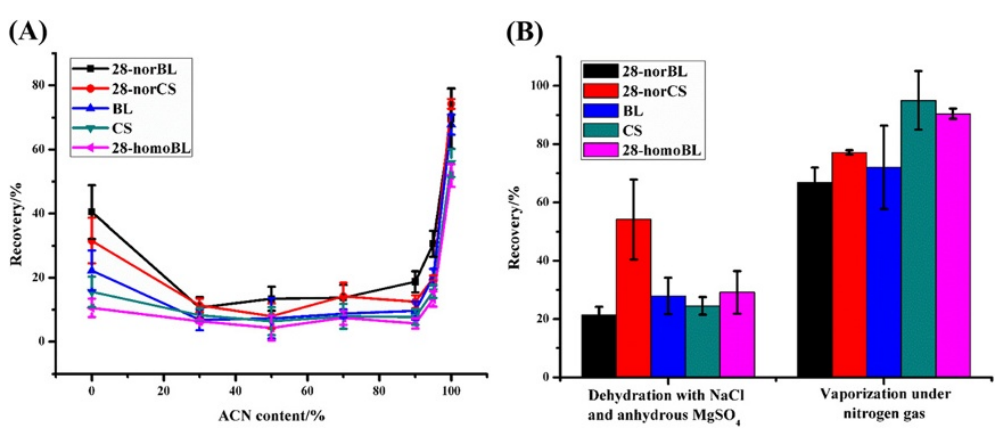

Figure 2 Effect of the water content in the sampling solution on the BR recoveries $(n=3)(A)$ and comparison of the effects of different dehydration strategies on plant extract $(\mathbf{n}=\mathbf{3})(B)$. BRs were spiked in the sampling solution at $1 \mathrm{ng} / \mathrm{mL}$ each. 

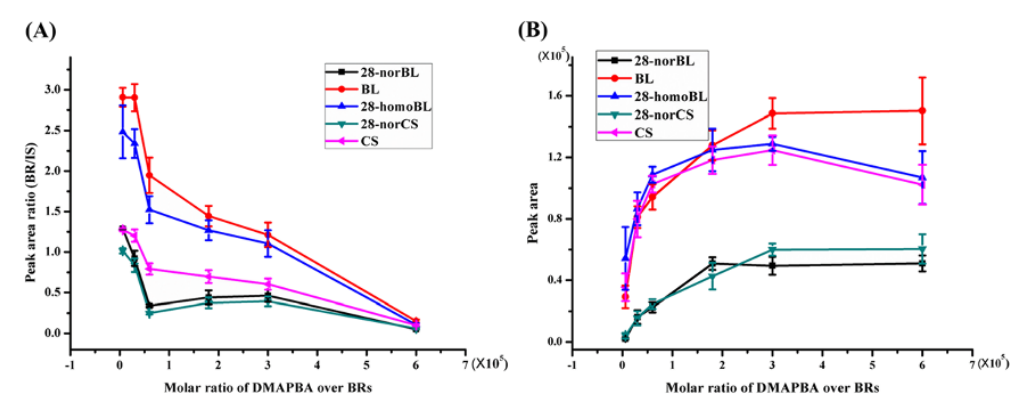

Figure 3 Effect of the DMAPBA amount on the derivatization efficiencies of BRs in acetonitrile $(n=3)(A)$ and in plant extract $(n=3)(B)$.

BRs were spiked in the sampling solution at $1 \mathrm{ng} / \mathrm{mL}$ each.

appeared at molar ratios (DMAPBA molar quantity by five BR molar quantity) above 300,000 (Figure 3B). We reason that in acetonitrile solution, as the molar ratio increased, more DMAPBA would enter the LC-MS/MS system during sample injection, which may suppress the ionization efficiencies of the $\mathrm{BR}$ derivatives. In plant extract, the existing $\mathrm{BR}$ analogues and other cis-diol-containing compounds might consume large amounts of DMAPBA; therefore, a greater amount of DMAPBA was required to guarantee high derivatization efficiencies of BRs. In this regard, $500 \mu \mathrm{g}$ DMAPBA (molar ratio 500,000/1) was selected.

$\mathrm{TiO}_{2} /$ MHMSS amounts were examined in the range of 10 to $100 \mathrm{mg}$. As shown in Figure 4A, the signal of the $\mathrm{BR}$ derivatives significantly increased as the $\mathrm{TiO}_{2} /$
MHMSS amounts increased from $10 \mathrm{mg}$ to $50 \mathrm{mg}$, and most of the signal of the BR derivatives remained nearly constant with greater amounts of $\mathrm{TiO}_{2} /$ MHMSS. Therefore, $50 \mathrm{mg} \mathrm{TiO}_{2} /$ MHMSS sorbent was used in the following experiments.

To obtain fast mass transfer between the sorbent and plant extract, the sampling, derivatization and desorption process were all performed under vortexing. Sampling time ranging from 30 seconds to 10 minutes was investigated. As shown in Figure 4B, the sampling time had no obvious effect on the extraction efficiencies; therefore, 30 seconds sampling was chosen. Similarly, the derivatization time and desorption time were also optimized (Figure 4C and D). The results showed that 30 seconds was enough for both procedures.

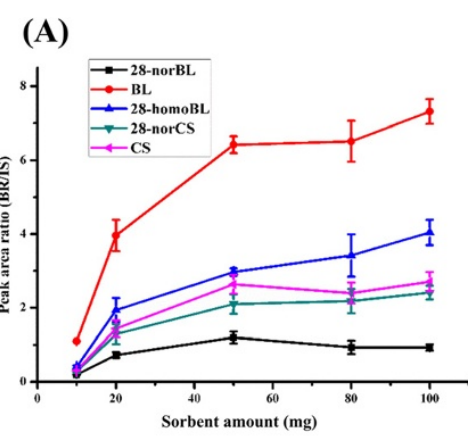

(B)
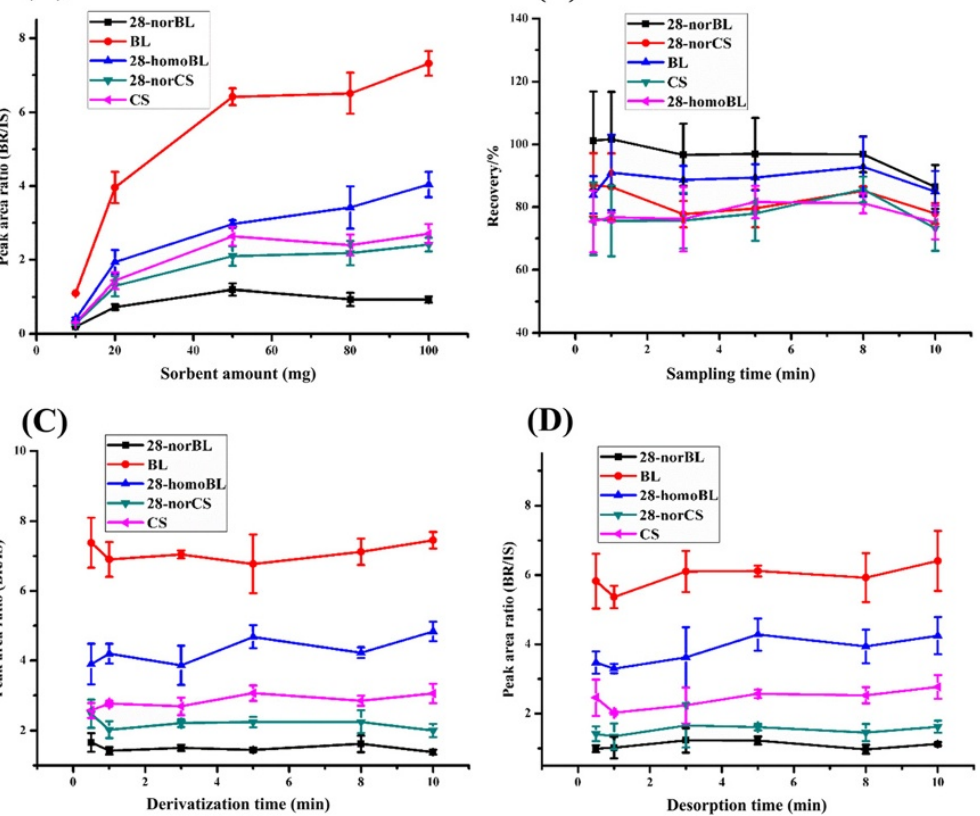

(D)

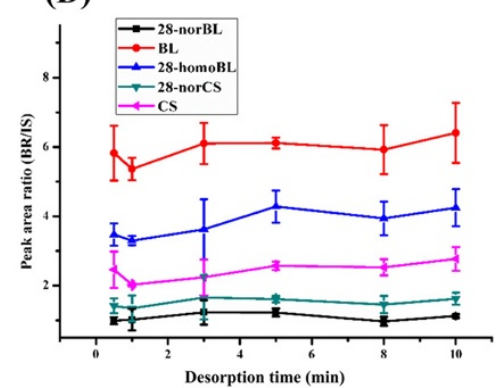

Figure 4 Effect of the sorbent amount on the extraction and derivatization efficiencies $(n=3)(A)$, effects of extraction time ( $n=3)(B)$, derivatization time $(n=3)(C)$ and desorption time $(n=3)(D)$ on the extraction and derivatization efficiencies. BRs were spiked in the sampling solution at $1 \mathrm{ng} / \mathrm{mL}$ each, and DMAPBA $(500 \mu \mathrm{g} / \mathrm{mL})$ was added for derivatization. 


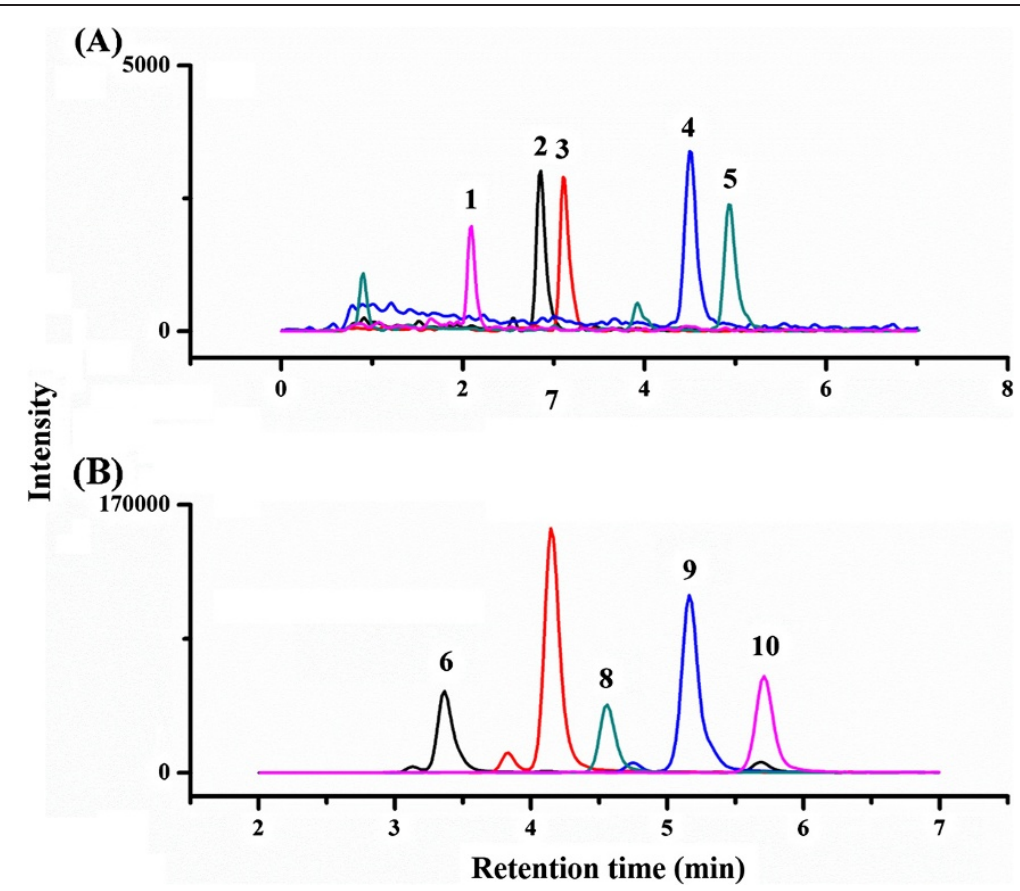

Figure 5 MRM chromatograms of the five BRs obtained without (A) or with MSPE-ISD (B). Peaks: 1. 28-norBL; 2. 28-norCS; 3. BL; 4. CS; 5. 28-homoBL; 6. 28-norBL derivative; 7. BL derivative; 8. 28-norCS derivative; 9. 28-homoBL derivative; 10. CS derivative.

On the basis of the above-described discussion, the optimal extraction conditions were as follows: $50 \mathrm{mg}$ $\mathrm{TiO}_{2} /$ MHMSS as the sorbents, BRs in acetonitrile $(1 \mathrm{~mL})$ as the sampling solution, $500 \mu \mathrm{g} / \mathrm{mL}$ DMAPBA in acetonitrile $(1 \mathrm{~mL})$ as the derivatization solution, $\mathrm{H}_{2} \mathrm{O}(0.5 \mathrm{~mL})$ as the desorption solution, $30 \mathrm{~s}$ for the extraction, derivatization and desorption time. In the optimal conditions, the MSPE-ISD process could be accomplished within 10 minutes.

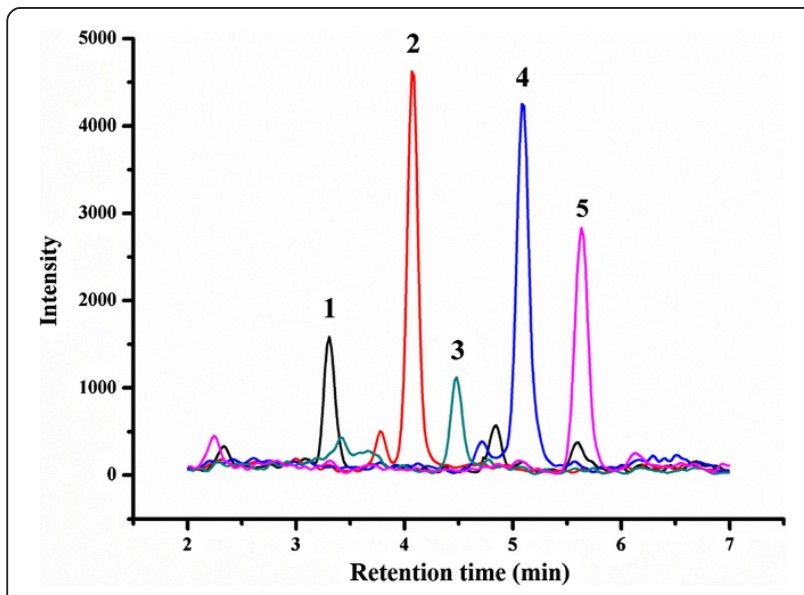

Figure 6 MRM chromatograms of the BRs in plant tissue $(100 \mathrm{mg}$ FW) treated with the MSPE-ISD method. The five BRs were all spiked at $0.1 \mathrm{ng} / \mathrm{mL}$. Peaks: 1. 28-norBL; 2. BL; 3. 28-norCS; 4. 28-homoBL; 5. CS.

\section{Sensitivity evaluation}

To evaluate the performance of MSPE-ISD, we compared the detection sensitivity of BRs with or without MSPE-ISD. After treatment, equal amount of BRs or BR-derivatives were injected into LC-MS/MS system. As shown in Figure 5, significant enhancement of the peak areas of five BRs could be achieved by MSPE-ISD. Specifically, after labeled with DMAPBA by ISD method, the peak areas of the BR derivatives increased by 18-48fold compared to that of BRs, which demonstrated the MS responses of BRs greatly increased.

\section{Method validation}

Because only two IS standards are commercially available and this is not sufficient to normalize the extraction and derivatization process, matrix-matched calibration curves were chosen as reference curves in the current

Table 1 Linearities, LODs and LOQs of the BR derivatives

\begin{tabular}{cccccccc}
\hline Analyte & $\begin{array}{c}\text { Linear range } \\
\text { (ng/mL) }\end{array}$ & \multicolumn{3}{c}{ Regression data } & LODs & LOQs \\
\cline { 3 - 5 } & Slope & Intercept & $\mathbf{R}$ value & (ng/L) & (ng/L) \\
\hline 28-norBL & $0.01-5$ & 6.9291 & 0.0448 & 0.9867 & 4.86 & 16.20 \\
BL & $0.01-5$ & 9.6684 & 0.0560 & 0.9981 & 1.94 & 6.48 \\
28-homoBL & $0.01-5$ & 7.4722 & 0.0669 & 0.9923 & 4.49 & 14.97 \\
28-norCS & $0.01-5$ & 6.0189 & 0.0262 & 0.9872 & 5.12 & 17.07 \\
CS & $0.01-5$ & 7.5004 & -0.0103 & 0.9992 & 4.23 & 14.08 \\
\hline
\end{tabular}


Table 2 Accuracy and precision (intra- and inter-day) for the determination of BRs in 0 . sativa $\mathrm{L}$ seedlings (100 mg FW)

\begin{tabular}{|c|c|c|c|c|c|c|c|c|c|}
\hline \multirow[t]{2}{*}{ Analyte } & \multicolumn{3}{|c|}{ Intra-day precision (RSD, $\%, n=3)$} & \multicolumn{3}{|c|}{ Inter-day precision (RSD, $\%, n=3$ ) } & \multicolumn{3}{|c|}{ Recovery $(\%, n=4)$} \\
\hline & $\begin{array}{c}\text { Low } \\
(0.5 \mathrm{ng} / \mathrm{g})\end{array}$ & $\begin{array}{l}\text { Medium } \\
(1 \mathrm{ng} / \mathrm{g})\end{array}$ & $\begin{array}{c}\text { High } \\
(10 \mathrm{ng} / \mathrm{g})\end{array}$ & $\begin{array}{c}\text { Low } \\
(0.5 \mathrm{ng} / \mathrm{g})\end{array}$ & $\begin{array}{l}\text { Medium } \\
(1 \mathrm{ng} / \mathrm{g})\end{array}$ & $\begin{array}{c}\text { High } \\
(10 \mathrm{ng} / \mathrm{g})\end{array}$ & $\begin{array}{l}\text { Low } \\
(0.5 \mathrm{ng} / \mathrm{g})\end{array}$ & $\begin{array}{l}\text { Medium } \\
(1 \mathrm{ng} / \mathrm{g})\end{array}$ & $\begin{array}{c}\text { High } \\
(10 \mathrm{ng} / \mathrm{g})\end{array}$ \\
\hline 28-norBL & 7.6 & 12.4 & 0.4 & 12.6 & 14.7 & 5.7 & 115.4 & 109.7 & 111.3 \\
\hline$B \mathrm{~L}$ & 5.7 & 7.4 & 8.0 & 1.3 & 10.5 & 4.1 & 102.9 & 111.0 & 113.7 \\
\hline 28-homoBL & 14.6 & 8.3 & 0.0 & 16.0 & 14.0 & 16.3 & 113.0 & 120.9 & 119.7 \\
\hline 28-norCs & 10.9 & 7.7 & 3.9 & 8.6 & 10.0 & 14.5 & 110.6 & 94.2 & 96.4 \\
\hline CS & 12.5 & 7.5 & 5.8 & 2.1 & 11.7 & 8.0 & 109.1 & 108.0 & 112.9 \\
\hline
\end{tabular}

study. The calibration curves were constructed by plotting the analyte/IS peak area ratio versus the concentrations with triplicate measurements from $100 \mathrm{mg}$ rice shoots. MRM chromatograms of the BRs in plant tissue spiked at $1 \mathrm{ng} / \mathrm{g}$ are shown in Figure 6. As shown in Table 1, satisfactory correlation coefficients were obtained with $\mathrm{R}$ values ranging from 0.9867 to 0.9992 . Moreover, the sensitivity of the method was evaluated by examining the limit of detection (LOD) and the limit of quantification (LOQ). The LOD was defined as the lowest detectable concentration with a signal-to-noise ratio of at least 3 , and the LOQ was defined as the lowest quantifiable concentration with a signal-to-noise ratio of at least 10 . The LODs and LOQs were in the range of 1.94 to 5.12 $\mathrm{ng} / \mathrm{L}$ and 6.48 to $17.07 \mathrm{ng} / \mathrm{L}$, respectively.

The reproducibility and accuracy of the proposed method were evaluated by intra- and inter-day precisions and recoveries. O. sativa $\mathrm{L}$ shoot extracts were spiked with $\mathrm{BR}$ standards (BL, CS, 28-norBL, 28-norCS, and 28-homoBL) at three concentration levels $(0.5 \mathrm{ng} / \mathrm{g}, 1 \mathrm{ng} / \mathrm{g}$, and $10 \mathrm{ng} / \mathrm{g})$. Three parallel extractions of a sample solution over 1 day gave the intra-day RSDs, and the inter-day RSDs were determined by extracting sample solutions that had been independently prepared for 3 continuous days. As shown in Table 2, acceptable precision was obtained, with RSD values below $16.3 \%$, indicating good reproducibility of the proposed method.

The recoveries were also obtained using $O$. sativa $\mathrm{L}$ extracts. The endogenous concentrations of BRs in $O$. sativa $\mathrm{L}$ extract were calculated based on the calibration curves. The spiked BR amounts were calculated by subtracting the endogenous concentration of each BR in the extract from the total concentration of BRs. Therefore, the recoveries were obtained by comparing the concentration of measured spiked BRs with the corresponding spiked values. As shown in Table 2, the relative recoveries were in the range of $94.2 \%$ to $119.7 \%$, demonstrating that the accuracy of the proposed method was satisfactory.

\section{Effect of plant tissue amount on BR detection}

With increased amounts of plant tissue, the endogenous BR contents also increased, which would facilitate BR detection. However, increased amounts of plant tissue may introduce more matrix interferents and therefore cause a negative impact on both extraction and detection. In this vein, an appropriate sample amount should be selected. Different amounts of plant tissue (50-500 mg) were treated by the MSPE-ISD method, and IS derivatives were

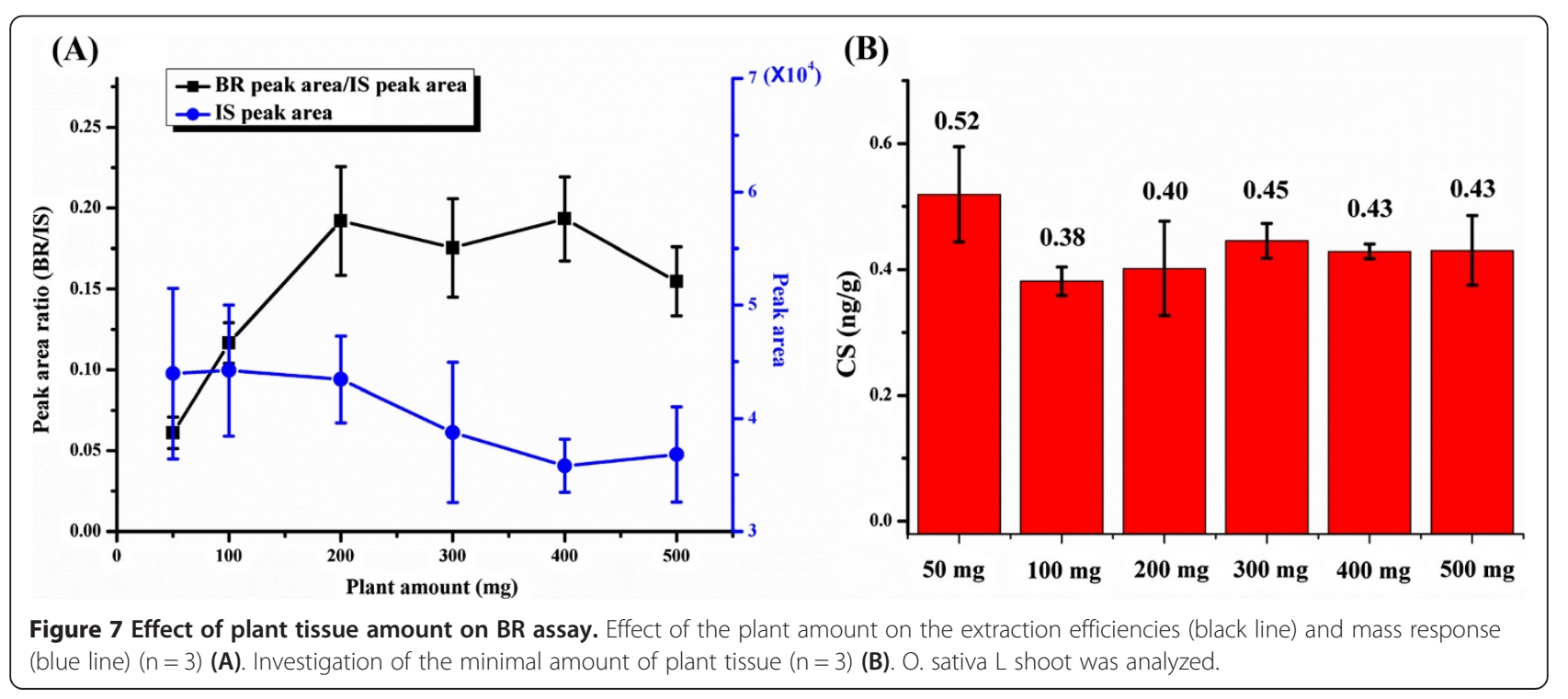


Table 3 Matrix effect of plant tissue analyzed by MSPEISD

\begin{tabular}{cc}
\hline Analytes & Matrix effect/\% \\
\hline 28-norBL & 85.9 \\
BL & 67.4 \\
28-homoBL & 76.0 \\
28-norCS & 93.1 \\
CS & 77.8 \\
\hline
\end{tabular}

Matrix effect $=$ BR/IS peak area ratio of the real sample over the BR/IS peak area ratio of a standard sample.

Plant extract (100 mg FW) and acetonitrile were both spiked with five BRs at $0.1 \mathrm{ng} / \mathrm{mL}$.

added prior to the UPLC-ESI-MS/MS analysis (Figure 7A). When matrix effects are negligible, the peak area of the IS derivatives should keep constant with the increase of plant amount, and the ratio of BR peak area to IS derivative peak area should increase linearly with the increase of plant amount. However, the matrix effects on the extraction and detection were obviously observed when using plant samples greater than $100 \mathrm{mg}$. The matrix effect of $100 \mathrm{mg}$ of plant tissue was 67.4 to 93.1\%, indicating that most of the hydrophobic matrix that might have a negative effect on ESI-MS ionization of BR derivatives had been removed using $100 \mathrm{mg}$ plant tissue (Table 3).

In some cases, a limited amount of plant tissue can be obtained for phytohormone analysis. To investigate the minimal amount of plant tissue required for endogenous BR detection, different amounts (from 50 to $500 \mathrm{mg}$ ) of $O$. sativa $\mathrm{L}$ shoots were used for the analysis of endogenous BRs by the MSPE-ISD method. As shown in Figure $7 \mathrm{~B}$, the results showed that the quantification of endogenous BRs was not affected by different amounts of $O$. sativa $\mathrm{L}$ shoot, but the signal-to-noise ratio of CS was near the LOQ when the amount was less than $50 \mathrm{mg}$. Therefore, $100 \mathrm{mg}$ was used for the real sample analysis.

\section{Analysis of BRs in plant tissues}

The BR contents in five plant samples (the control and drought $O$. sativa L shoot, O. sativa L. cv. 9311-A shoot, O. sativa L. cv. 9311-B shoot and Brassica napus L. shoot) were determined by the MSPE-ISD method. The results showed that both $\mathrm{CS}$ and $\mathrm{BL}$ were detectable in Oryza sativa L. (control) and Brassica napus L. shoots, and CS was detected in Oryza sativa L. (drought), Oryza sativa L. cv. 9311-A and Oryza sativa L. cv. 9311-B shoots (Table 4), which demonstrates that our proposed method is suitable for the sensitive analysis of low contents of BRs in plant tissue.

Furthermore, we designed a biological experiment to test the proposed method. BRs were reported to take part in plant photomorphogenesis [31]. In light, the related genes in BR biosynthesis pathway were inhibited, while in dark these genes got activated. To investigate the effect of light periods on the BR levels, we grew $O$. sativa $\mathrm{L}$ under three different light periods (all dark, $8 \mathrm{~h}$ light/16 $\mathrm{h}$ dark, $16 \mathrm{~h}$ light/ $8 \mathrm{~h}$ dark) and observed different growth patterns of these $O$. sativa L shoots. In dark, the seedlings showed an etiolation pattern that did not produce chlorophyll but instead elongated upwards. In light, the seedlings were all green and relatively short. The endogenous BR contents of the three samples were analyzed by our proposed method. As shown in Table 5, the BR contents showed no difference between the seedlings of the $8 \mathrm{~h}$ light $/ 16 \mathrm{~h}$ dark and $16 \mathrm{~h}$ light $/ 8 \mathrm{~h}$ dark conditions. Remarkably, the CS content was reduced sharply in the all dark condition, whereas $0.04 \mathrm{ng} / \mathrm{g} \mathrm{BL}$ was observed. BL was the final product of the BR biosynthesis pathway and was reported to be the most active among all of the BRs. The quantitative results of $B R$ s revealed that BR synthesis gene got activated, and CS was converted into BL in the absence of light, which was coincided with the reported physiological function of BRs, demonstrating the feasibility and accuracy of the proposed BR assay.

\section{Method comparison}

We summarized the representative articles published in the last four years for BR analysis using different methods in Table $6[7,9,30,32]$, and the analytical time, LODs and the amount of samples were compared. The proposed MSPE-ISD-UPLC-MS/MS assay could be finished within an hour, and only $100 \mathrm{mg}$ fresh weight of plant tissues were required for the quantification of endogenous BRs. Compared with the published methods, the proposed method showed significant advantages in both the sensitivity and the analysis speed.

\section{Conclusion}

In this study, we developed an MSPE-ISD method for the determination of endogenous phytohormones in plant tissues. Using $\mathrm{TiO}_{2} /$ MHMSS as both an extraction sorbent and microreactor, the extraction and derivatization processes and magnetic separation were successfully combined. The method largely simplified the sample

Table 4 Amounts of endogenous BR in various plant tissues

\begin{tabular}{|c|c|c|c|c|c|}
\hline Analyte & O. sativa L. (control) & O. sativa L. (drought) & B. napus L. shoot & O. sativa YTA shoot & O. sativa YTB shoot \\
\hline CS & $0.09 \pm 0.01$ & $0.11 \pm 0.04$ & $0.17 \pm 0.02$ & $0.19 \pm 0.02$ & $0.26 \pm 0.02$ \\
\hline$B L$ & $0.04 \pm 0.01$ & n.d. & $0.13 \pm 0.01$ & n.d. & n.d. \\
\hline
\end{tabular}


Table 5 Amounts of endogenous BR in O. sativa $L$ shoots under three different light conditions

\begin{tabular}{cccc}
\hline Analyte & $\begin{array}{c}\text { O. sativa } \mathrm{L} \\
\text { shoot with } 16 \mathrm{~h} \\
\text { light } / \mathbf{8} \text { h dark }\end{array}$ & $\begin{array}{c}\text { O. sativa } \mathrm{L} \\
\text { shoot with } \mathbf{8} \mathbf{h} \\
\text { light } / 16 \mathrm{~h} \text { dark }\end{array}$ & $\begin{array}{c}\text { O. sativa } \mathrm{L} \\
\text { shoot with } \\
\text { all dark }\end{array}$ \\
\hline CS & $0.10 \pm 0.02$ & $0.12 \pm 0.01$ & $0.04 \pm 0.00$ \\
BL & n.d. & n.d. & $0.04 \pm 0.01$ \\
\hline
\end{tabular}

Unit: ng/g; n.d., not detectable.

preparation procedure and the BR assay can be accomplished within 1 hour. In the meantime, the MS response of BRs was significantly improved due to derivatization with 4-DMAPBA, which can benefit the quantification of BRs with a small amount of plant tissue $(100 \mathrm{mg}$ fresh weight in the current study). We then successfully determined the concentration of endogenous BRs in various plant tissues. The developed MSPE-ISD technique may also have potential for the determination of a wide range of analytes in other complex biological and environmental sample matrices.

\section{Methods}

\section{Chemicals and reagents}

Standard BRs and stable isotope-labeled standards (IS), including 28-norbrassinolide (28-norBL, purity > 98\%), 28-norcastasterone (28-norCS, purity $>98 \%$ ), 28 homobrassinolde (28-homoBL, purity $>95 \%$ ), brassinolide (BL, purity $>95 \%$ ), castasterone (CS, purity $>98 \%$ ), $\left[{ }^{2} \mathrm{H}_{3}\right] \mathrm{BL}$ and $\left[{ }^{2} \mathrm{H}_{3}\right] \mathrm{CS}$, were purchased from Olchemim Ltd. (Olomouc, Czech Republic). All of the BRs standards and stable isotope-labeled standards were dissolved in acetonitrile to obtain stock solutions at the concentration of $200 \mathrm{ng} / \mathrm{mL}$ for each. Working solutions were obtained by appropriate dilution of the stock solutions.

Chromatographic grade acetonitrile was obtained from Tedia Co. (Fairfield, OH, USA). Ultrapure water was purified by a Milli-Q water purification system (Millipore, Milford, MA, USA). 4-(N,N-dimethyamino) phenylboronic acid (DMAPBA) was purchased from I\&K Scientific Ltd (Beijing, China). Cetyltrimethylammonium bromide (CTAB), sodium silicate nonahydrate $\left(\mathrm{Na}_{2} \mathrm{SiO}_{3} \cdot 9 \mathrm{H}_{2} \mathrm{O}\right)$, iron nitrate nonahydrate $\left(\mathrm{Fe}\left(\mathrm{NO}_{3}\right)_{3} \cdot 9 \mathrm{H}_{2} \mathrm{O}\right)$, ethylene glycol
(EG), ammonium hexfluorotitanate $\left(\left(\mathrm{NH}_{4}\right)_{2} \mathrm{TiF}_{6}\right)$, boric acid $\left(\mathrm{H}_{3} \mathrm{BO}_{3}\right)$ and ethyl acetate were all of analytical grade and supplied by Sinopharm Chemical Reagent Co., Ltd (Shanghai, China). Titania spheres (Titansphere, $5 \mu \mathrm{m}$ ) were purchased from GL Sciences Inc. (Tokyo, Japan). Silica spheres $\left(\mathrm{SiO}_{2}, 200-300\right.$ mesh) were obtained from Qingdao Haiyang Chemical Co., Ltd (Qingdao, China).

\section{Plant materials}

Nine types of plant leaves, including rice (Oryza sativa L. (O. sativa $\mathrm{L})$ ) and rape (B. napus $\mathrm{L})$, were analyzed in this study. Three-month-old wild-type B. napus L leaves were harvested from the ground. Two rice mutant shoots (Oryza sativa ssp. Indica cv. YueTai A (YTA) (Sterile Lines) (O. sativa YTA) and Oryza sativa ssp. indica cv. YueTai B (maintainer line) (O. sativa YTB)) were grown in the field for 3 months and harvested. Wild-type O. sativa L shoots, under three different light periods (all dark, $8 \mathrm{~h}$ light $/ 16 \mathrm{~h}$ dark, $16 \mathrm{~h}$ light $/ 8 \mathrm{~h}$ dark), were grown in a cultivation room at $25^{\circ} \mathrm{C}$ (night) and $30^{\circ} \mathrm{C}$ (day) for 2 weeks. The drought and control groups of $O$. sativa $\mathrm{L}$ were both germinated and grown in the cultivation room at $25^{\circ} \mathrm{C}$ (night) and $30^{\circ} \mathrm{C}$ (day) for 2 weeks. The seedlings grown without water were called the drought group, and the seedlings which were watered on time were called the control group. All plant materials were immediately frozen in liquid nitrogen after harvest and were then stored at $-80^{\circ} \mathrm{C}$.

\section{Preparation of hydrophilic magnetic sorbents}

$\mathrm{TiO}_{2}$-coated magnetic hollow mesoporous silica spheres (MHMSS) were prepared according to a previously reported method with minor modification [33]. Briefly, CTAB (19.6 g) and $\mathrm{Na}_{2} \mathrm{SiO}_{3} \cdot 9 \mathrm{H}_{2} \mathrm{O}(23.2 \mathrm{~g})$ were dissolved in water $(337 \mathrm{~mL})$ to form a clear solution at $30^{\circ} \mathrm{C}$. Then, ethyl acetate $(35 \mathrm{~mL})$ was quickly added, followed by vigorous stirring for 30 seconds. After standing at $30^{\circ} \mathrm{C}$ for 5 hours, the mixture was refluxed at $90^{\circ} \mathrm{C}$ for 48 hours. Finally, the mixture was filtered and washed several times with ethanol. The filtered HMSS was dried in a vacuum oven and then calcined at $550^{\circ} \mathrm{C}$ for 5 hours. Magnetic nanoparticles were introduced

Table 6 Comparison of different BR analytical methods

\begin{tabular}{|c|c|c|c|c|c|}
\hline Pretreatment method & Separation/detection & Analyte & LOD & $\begin{array}{c}\text { Amount of } \\
\text { plant tissues }\end{array}$ & Analysis time \\
\hline LLE-MSPE-derivatization [9] & LC-FLD & 24-epiBL & $0.12 \mathrm{ng}$ & $50 \mathrm{~g}$ & More than 3 hours \\
\hline SPE-ultrafiltration-SPE-derivatization [7] & Online trapping-UPLC-MS/MS & 28-epihomoBL & $0.2 \mathrm{pg}$ & $400 \mathrm{mg}$ & 7 hours \\
\hline MCX SPE-MAX SPE-derivatization [32] & UPLC-MS/MS & $\begin{array}{l}\text { BL, CS, teasterone (TE) } \\
\text { typhasterol (TY) }\end{array}$ & $1.5-3.9 \mathrm{pg}$ & $1 \mathrm{~g}$ & 1 day \\
\hline $\begin{array}{l}\text { On-line two-dimensional microscale SPE-on } \\
\text { column derivatization-HPLC-MS/MS [30] }\end{array}$ & On-line-HPLC-MS/MS & $\begin{array}{l}\text { 24-epiBL, 24-epiCS, } \\
\text { 6-deoxo-24-epiCS,TE, TY }\end{array}$ & $1.4-6.6 \mathrm{pg}$ & $225 \mathrm{mg}$ & 40 minutes \\
\hline MSPE coupled with ISD (this work) & UPLC-MS/MS & $\begin{array}{l}\text { 28-norBL, 28-norCS, } \\
\text { 28-homoBL, BL, CS }\end{array}$ & $0.1-0.3 \mathrm{pg}$ & $100 \mathrm{mg}$ & 1 hour \\
\hline
\end{tabular}




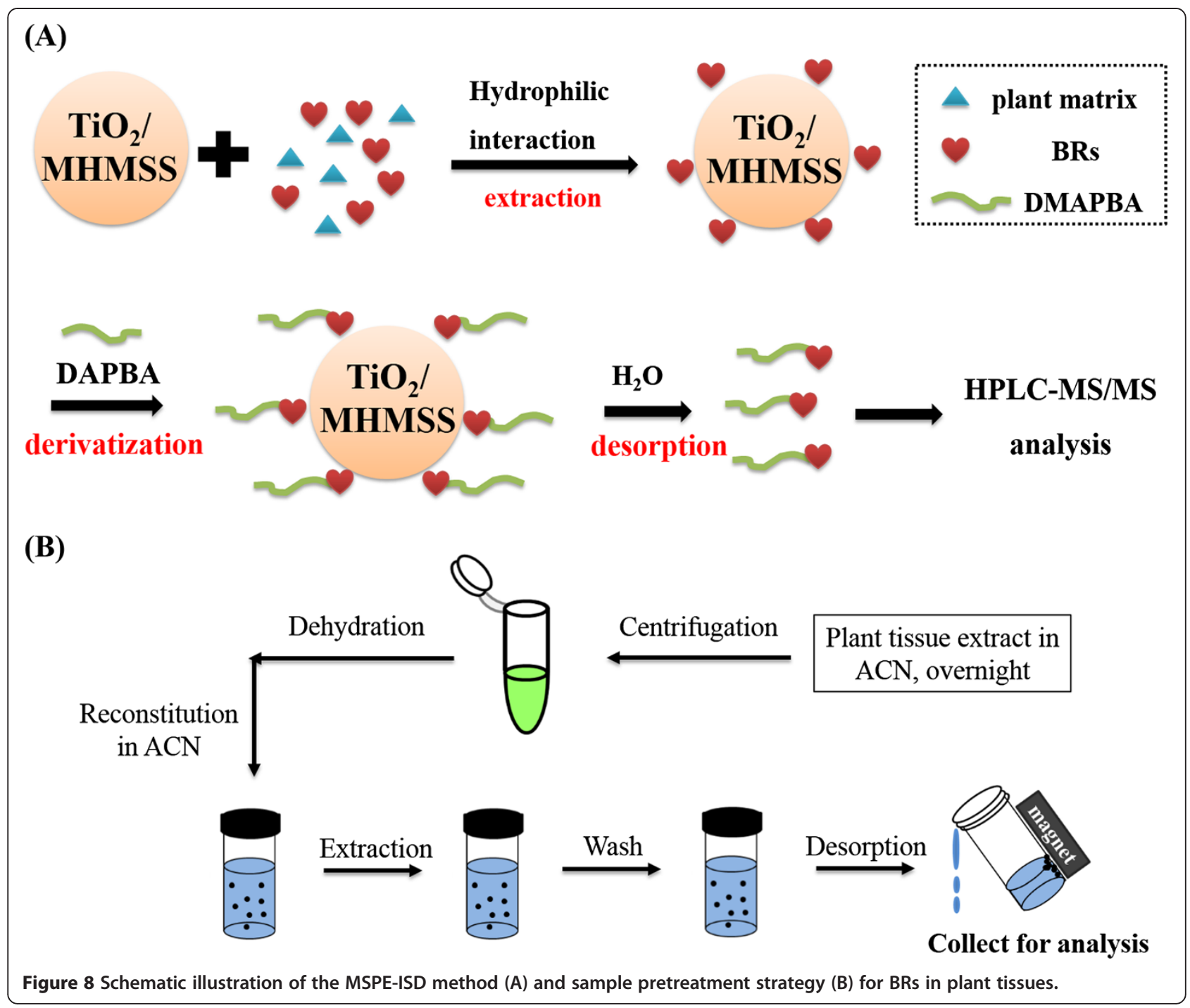

into the hollow core of HMSS through a vacuum impregnation of $\mathrm{Fe}\left(\mathrm{NO}_{3}\right)_{3}$. HMSS $(2.4 \mathrm{~g})$ was soaked in Fe $\left(\mathrm{NO}_{3}\right)_{3} \cdot 9 \mathrm{H}_{2} \mathrm{O}$ aqueous solution $(24 \mathrm{~g} / \mathrm{L}, 200 \mathrm{~mL})$. The suspension was heated in a microwave oven until boiling and then cooled in an ice water mixture, allowing the $\mathrm{Fe}^{3+}$ to enter the hollow core of the HMSS. The process was repeated several times until the water completely dried. Subsequently, the product was washed with 10 $\mathrm{mL}$ ethanol twice and dried again. The product was impregnated with $1 \mathrm{~mL}$ ethylene glycol up to incipient wetness. The impregnated sample was then subjected to heat treatment under nitrogen atmosphere at $450^{\circ} \mathrm{C}$ for

Table 7 Optimized MRM parameters of seven BR derivatives by UPLC-ESI-MS/MS

\begin{tabular}{|c|c|c|c|c|c|c|c|c|c|c|}
\hline \multirow[t]{2}{*}{ Analyte } & \multicolumn{5}{|c|}{ Quantification } & \multicolumn{5}{|c|}{ Confirmation } \\
\hline & $\mathrm{Q} 1(\mathrm{~m} / \mathrm{z})$ & Q3 (m/z) & Q1 pre bias/V & $\mathrm{CE}$ & Q3 pre bias/V & $\mathrm{Q1}(\mathrm{m} / \mathrm{z})$ & $\mathrm{Q} 3(\mathrm{~m} / \mathrm{z})$ & Q1 pre bias/V & $\mathrm{CE}$ & Q3 pre bias/V \\
\hline 28-norBL & 596.4 & 190.1 & -30 & -44 & -20 & 596.4 & 246.1 & -30 & -34 & -17 \\
\hline$B L$ & 610.4 & 190.2 & -32 & -41 & -13 & 610.4 & 122.1 & -32 & -40 & -24 \\
\hline 28-homoBL & 624.4 & 190.2 & -32 & -41 & -20 & 624.4 & 418.0 & -32 & -39 & -23 \\
\hline 28-norCS & 580.4 & 190.1 & -30 & -49 & -21 & 580.4 & 562.4 & -30 & -30 & -28 \\
\hline CS & 594.4 & 190.1 & -30 & -44 & -20 & 594.4 & 576.4 & -30 & -32 & -22 \\
\hline${ }^{2} \mathrm{H}_{3} \mathrm{BL}$ & 613.4 & 190.4 & -34 & -51 & -13 & 613.4 & 345.4 & -34 & -38 & -16 \\
\hline${ }^{2} \mathrm{H}_{3} \mathrm{CS}$ & 597.4 & 194.4 & -32 & -46 & -13 & 597.4 & 579.6 & -32 & -32 & -22 \\
\hline
\end{tabular}


2 hours. Finally, $\mathrm{TiO}_{2}$ was loaded onto the obtained MHMSS through the liquid phase deposition method. MHMSS (2.0 g) was added into a solution $(200 \mathrm{~mL})$ containing $0.1 \mathrm{M}\left(\mathrm{NH}_{4}\right)_{2} \mathrm{TiF}_{6}$ and $0.3 \mathrm{M} \mathrm{H}_{3} \mathrm{BO}_{3}$ in a PTFE container. After keeping under vacuum conditions for $1 \mathrm{~h}$, the mixture was heated at $35^{\circ} \mathrm{C}$ for $12 \mathrm{~h}$ under continuous shaking. The resulting composite was washed with water thoroughly and dried at $60^{\circ} \mathrm{C}$ in a vacuum oven for $6 \mathrm{~h}$. The resultant $\mathrm{TiO}_{2} / \mathrm{MHMSS}$ was obtained by heat treatment under nitrogen up to $300^{\circ} \mathrm{C}$ at the rate of $1 \mathrm{~K} / \mathrm{min}$ and was then kept at $300^{\circ} \mathrm{C}$ for $2 \mathrm{~h}$.

Nano-scale $\mathrm{Fe}_{3} \mathrm{O}_{4}$ was prepared through the solvothermal method according to a previously reported method [34]. $\mathrm{FeCl}_{3} \cdot 6 \mathrm{H}_{2} \mathrm{O}(5.0 \mathrm{~g})$ was dissolved in EG $(100 \mathrm{~mL})$ to form a clear solution. Then, NaAc $(15.0 \mathrm{~g})$ and ED $(50 \mathrm{~mL})$ were added to the solution. After vigorously stirring for $30 \mathrm{~min}$, the homogeneous mixture was sealed in a Teflon-lined stainless-steel autoclave and was heated to $200^{\circ} \mathrm{C}$ for 8 hours. The product was magnetically collected and washed with water/ethanol several times and vacuumdried at $60^{\circ} \mathrm{C}$ for $6 \mathrm{~h}$.

\section{MSPE-ISD procedure for the determination of BRs in plant tissue}

The schematic illustrations of MSPE-ISD (A) and the sample pretreatment strategy (B) are depicted in Figure 8. Plant tissue $(100 \mathrm{mg}$ fresh weight $(\mathrm{FW}))$ was smashed with a mortar and pestle in liquid nitrogen. The powdered sample was extracted at $-20^{\circ} \mathrm{C}$ overnight with acetonitrile $(1 \mathrm{~mL})$ containing $\left[{ }^{2} \mathrm{H}_{3}\right] \mathrm{BL}$ and $\left[{ }^{2} \mathrm{H}_{3}\right] \mathrm{CS}(0.4$ ng each) as IS for quantification. After centrifugation at $3,500 \mathrm{~g}$ for $10 \mathrm{~min}$, the supernatant was collected in a $1.5-\mathrm{mL}$ vial followed by evaporation to dryness under a mild nitrogen gas stream. The residue was re-dissolved with acetonitrile $(1 \mathrm{~mL})$ for the following MSPE-ISD process.

$\mathrm{TiO}_{2} /$ MHMSS $(50 \mathrm{mg}$ ) was added to a $15-\mathrm{mL}$ glass vial and activated with acetonitrile before use. Subsequently, the aforementioned plant extract $(1 \mathrm{~mL})$ was added into the vial and vortexed vigorously for 30 seconds to form a homogenous dispersive solution. The supernatant was separated and discarded by applying a magnet. Acetonitrile $(1 \mathrm{~mL})$ was added to wash the residual matrix interferences on the surface with 30 seconds of vortexing and was then disposed of. The washing process was repeated twice. Subsequently, DMAPBA-acetonitrile solution $(500 \mu \mathrm{g} / \mathrm{mL}$, $1 \mathrm{~mL}$ ) was added to the vial for ISD by vortexing for 30 seconds. Finally, water $(0.5 \mathrm{~mL})$ was added to the mixture solution to elute BR derivatives from the sorbents by 30 seconds of vortexing. The desorption solution was magnetically separated and evaporated to dryness under a mild nitrogen gas flow at $35^{\circ} \mathrm{C}$. The residue was dissolved in acetonitrile $/ \mathrm{H}_{2} \mathrm{O}(50 \mu \mathrm{L}, 1 / 1 \mathrm{v} / \mathrm{v})$, and then $20 \mu \mathrm{L}$ was used for the analysis by UPLC-ESI-MS/MS.

\section{UPLC-ESI-MS/MS analysis}

The mass spectrometry analysis was performed on a UPLC-ESI (+)-MS/MS system consisting of a Shimadzu LC-30AD HPLC system (Tokyo, Japan) with two 30AD pumps, an SIL-30AC auto sampler, a CTO-30A thermostat column compartment, a DGU-20 $\mathrm{A}_{5 \mathrm{R}}$ degasser, and a Shimadzu MS-8040 mass spectrometer (Tokyo, Japan) with an electrospray ionization source (Turbo Ionspray). The separation of BRs was achieved on a Shim-pack ODS column $(75 \times 2.0 \mathrm{~mm}$ id, $1.6 \mu \mathrm{m}$, Shimadzu, Tokyo, Japan). The column oven temperature was set at $40^{\circ} \mathrm{C}$. Mobile phases A and B were $0.1 \%$ formic acid in water and acetonitrile, respectively. An isocratic elution of $85 \% \mathrm{~B}$ at $0.2 \mathrm{~mL} / \mathrm{min}$ for 7 minutes was employed. The injection volume was $20 \mu \mathrm{L}$.

All BRs were quantified by multiple reaction monitoring (MRM) in the positive mode. The optimal ESI source conditions were as follows: DL temperature $250^{\circ} \mathrm{C}$, heat block temperature $400^{\circ} \mathrm{C}$, nebulizing gas $3 \mathrm{~L} / \mathrm{min}$ and drying gas $15 \mathrm{~L} / \mathrm{min}$. The MRM mass spectrometric parameters are summarized in Table 7. Data were acquired by Labsolutions software (version 5.53 sp2, Shimadzu, Tokyo, Japan).

\section{Competing interests}

The authors declare that they have no competing interests.

\section{Authors' contributions}

JD, JHW and YQF conceived and designed the method. JD, JHW and JFL carried out the experiments. JD, JHW and YQF wrote the manuscript. BFY and YQF revised the manuscript. All authors read and approved the final manuscript.

\section{Acknowledgments}

The authors are thankful for the financial support from the National Natural Science Foundation of China (91217309, 91017013), and the Fundamental Research Funds for the Central Universities.

\section{Author details}

'Key Laboratory of Analytical Chemistry for Biology and Medicine (Ministry of Education), Department of Chemistry, Wuhan University, Wuhan 430072 .

China. ${ }^{2}$ Chinese Acad Sci, Key Lab Plant Germplasm Enhancement \& Specialty A, Wuhan Bot Garden, Wuhan 430074, China. ${ }^{3}$ College of Chemical Engineering, Wuhan Textile University, Wuhan 430200, China.

Received: 31 July 2014 Accepted: 30 October 2014

Published: 24 November 2014

\section{References}

1. Bajguz A, Hayat S: Effects of brassinosteroids on the plant responses to environmental stresses. Plant Physiol Biochem 2009, 47(1):1-8.

2. Krishna P: Brassinosteroid-mediated stress responses. J Plant Growth Regul 2003, 22(4):289-297.

3. Stephen D, Christain SH: Hormone signalling crosstalk in plant growth regulation. Curr Biol 2011, 21(9):R365-R373.

4. Bishop GJ, Yokota T: Plants steroid hormones, brassinosteroids: current highlights of molecular aspects on their synthesis/metabolism, transport, perception and response. Plant Cell Physiol 2001, 42(2):114-120

5. Robert-Seilaniantz A, Grant M, Jones JDG: Hormone Crosstalk in Plant Disease and Defense: More Than Just JASMONATE-SALICYLATE Antagonism. In Annual Review of Phytopathology, Vol 49. Edited by VanAlfen NK, Bruening G, Leach JE. 317-343. vol. 49

6. Nováková L, Vlčková H: A review of current trends and advances in modern bio-analytical methods: chromatoraphy and sample preparation. Anal Chim Acta 2009, 656(1-2):8-35. 
7. Huo F, Wang X, Han Y, Bai Y, Zhang W, Yuan H, Liu H: A new derivatization approach for the rapid and sensitive analysis of brassinosteroids by using ultra high performance liquid chromatography-electrospray ionization triple quadrupole mass spectrometry. Talanta 2012, 99:420-425.

8. Swaczynova J, Novak O, Hauserova E, Fuksova K, Sisa M, Kohout L, Strnad M: New techniques for the estimation of naturally occurring brassinosteroids. J Plant Growth Regul 2007, 26(1):1-14.

9. Zhang Z, Zhang Y, Tan W, Li G, Hu Y: Preparation of styrene-co-4-vinylpyridine magnetic polymer beads by microwave irradiation for analysis of trace 24-epibrassinolide in plant samples using high performance liquid chromatography. J Chromatogr A 2010, 1217(42):6455-6461.

10. Xin PY, Yan JJ, Fan JS, Chu JF, Yan CY: A dual role of boronate affinity in high-sensitivity detection of vicinal diol brassinosteroids from sub-gram plant tissues via UPLC-MS/MS. Analyst 2013, 138(5):1342-1345.

11. Wang X, Ma Q, Li M, Chang CL, Bai Y, Feng YQ, Liu HW: Automated and sensitive analysis of 28-epihomobrassinolide in Arabidopsis thaliana by on-line polymer monolith microextraction coupled to liquid chromatography-mass spectrometry. J Chromatogr A 2013, 1317:121-128.

12. Atapattu SN, Rosenfeld JM: Solid phase analytical derivatization as a sample preparation method. J Chromatogr A 2013, 1296:204-213.

13. Rosenfeld JM: Solid-phase analytical derivatization: enhancement of sensitivity and selectivity of analysis. J Chromatogr A 1999, 843(1-2):19-27.

14. Park Y-K, Choi K, Ahmed AYBH, Alothman ZA, Chung DS: Selective preconcentration of amino acids and peptides using single drop microextraction in-line coupled with capillary electrophoresis. J Chromatogr A 2010, 1217(20):3357-3361.

15. Sharma N, Jain A, Singh VK, Verma KK: Solid-phase extraction combined with headspace single-drop microextraction of chlorophenols as their methyl ethers and analysis by high-performance liquid chromatography-diode array detection. Talanta 2011, 83(3):994-999.

16. Poole CF: New trends in solid-phase extraction. Trac-Trends Anal Chem 2003, 22(6):362-373.

17. Salvador A, Moretton C, Piram A, Faure R: On-line solid-phase extraction with on-support derivatization for high-sensitivity liquid chromatography tandem mass spectrometry of estrogens in influent/effluent of wastewater treatment plants. J Chromatogr A 2007, 1145(1-2):102-109.

18. Ito R, Kawaguchi M, Honda H, Koganei Y, Okanouchi N, Sakui N, Saito K, Nakazawa H: Hollow-fiber-supported liquid phase microextraction with in situ derivatization and gas chromatography-mass spectrometry for determination of chlorophenols in human urine samples. J Chromatogr $B$ Analyt Technol Biomed Life Sci 2008, 872(1-2):63-67.

19. Meng L, Liu X, Wang B, Shen G, Wang Z, Guo M: Simultaneous derivatization and extraction of free cyanide in biological samples with home-made hollow fiber-protected headspace liquid-phase microextraction followed by capillary electrophoresis with UV detection. J Chromatogr B Analyt Technol Biomed Life Sci 2009, 877(29):3645-3651.

20. Zhang $\mathrm{H}-\mathrm{J}$, Huang J-F, Lin B, Feng Y-Q: Polymer monolith microextraction with in situ derivatization and its application to high-performance liquid chromatography determination of hexanal and heptanal in plasma. J Chromatogr A 2007, 1160(1-2):114-119.

21. Awan MA, Fleet I, Thomas CLP: Determination of biogenic diamines with a vaporisation derivatisation approach using solid-phase microextraction gas chromatography-mass spectrometry. Food Chem 2008, 111(2):462-468.

22. Campins-Falco P, Herraez-Hernandez R, Verdu-Andres J, Chafer-Pericas C: On-line determination of aliphatic amines in water using in-tube solid-phase microextraction-assisted derivatisation in in-valve mode for processing large sample volumes in LC. Anal Bioanal Chem 2009, 394(2):557-565.

23. Magi E, Di Carro M, Liscio C: Passive sampling and stir bar sorptive extraction for the determination of endocrine-disrupting compounds in water by GC-MS. Anal Bioanal Chem 2010, 397(3):1335-1345.

24. Ding J, Gao Q, Li XS, Huang W, Shi ZG, Feng YQ: Magnetic solid-phase extraction based on magnetic carbon nanotube for the determination of estrogens in milk. J Sep Sci 2011, 34(18):2498-2504.

25. Li XS, Wu JH, Xu LD, Zhao Q, Luo YB, Yuan BF, Feng YQ: A magnetite/ oxidized carbon nanotube composite used as an adsorbent and a matrix of MALDI-TOF-MS for the determination of benzo[a]pyrene. Chem Commun 2011, 47(35):9816-9818

26. Ding J, Gao QA, Luo D, Shi ZG, Feng YQ: n-Octadecylphosphonic acid grafted mesoporous magnetic nanoparticle: Preparation, characterization, and application in magnetic solid-phase extraction. J Chromatogr A 2010, 1217(47):7351-7358
27. Gao Q, Luo D, Ding J, Feng YQ: Rapid magnetic solid-phase extraction based on magnetite/silica/poly(methacrylic acid-co-ethylene glycol dimethacrylate) composite microspheres for the determination of sulfonamide in milk samples. J Chromatogr A 2010, 1217(35):5602-5609.

28. Zhao Q, Wei F, Xiao N, Yu Q-W, Yuan B-F, Feng Y-Q: Dispersive microextraction based on water-coated $\mathrm{Fe} 3 \mathrm{O} 4$ followed by gas chromatography mass spectrometry for determination of 3-monochloropropane-1,2-diol in edible oils. J Chromatogr A 2012, 1240:45-51.

29. Ding J, Mao L, Yuan BF, Feng YQ: A selective pretreatment method for determination of endogenous active brassinosteroids in plant tissues: double layered solid phase extraction combined with boronate affinity polymer monolith microextraction. Plant Methods 2013, 9:13.

30. Wu Q, Wu D, Shen Z, Duan C, Guan Y: Quantification of endogenous brassinosteroids in plant by on-line two-dimensional microscale solid phase extraction-on column derivatization coupled with high performance liquid chromatography-tandem mass spectrometry. J Chromatogr A 2013, 1297:56-63.

31. Ashraf M, Akram NA, Arteca RN, Foolad MR: The physiological, biochemical and molecular roles of Brassinosteroids and salicylic acid in plant processes and salt tolerance. Crit Rev Plant Sci 2010, 29(3):162-190.

32. Xin PY, Yan JJ, Fan JS, Chu JF, Yan CY: An improved simplified high-sensitivity quantification method for determining brassinosteroids in different tissues of rice and Arabidopsis. Plant Physiol 2013, 162(4):2056-2066.

33. Wu JH, Li XS, Zhao Y, Gao QA, Guo L, Feng YQ: Titania coated magnetic mesoporous hollow silica microspheres: fabrication and application to selective enrichment of phosphopeptides. Chem Commun 2010, 46(47):9031-9033.

34. Guo S, Li D, Zhang L, Li J, Wang E: Monodisperse mesoporous superparamagnetic single-crystal magnetite nanoparticles for drug delivery. Biomaterials 2009, 30(10):1881-1889.

doi:10.1186/1746-4811-10-39

Cite this article as: Ding et al:: Improved methodology for assaying brassinosteroids in plant tissues using magnetic hydrophilic material for both extraction and derivatization. Plant Methods 2014 10:39.

\section{Submit your next manuscript to BioMed Central and take full advantage of:}

- Convenient online submission

- Thorough peer review

- No space constraints or color figure charges

- Immediate publication on acceptance

- Inclusion in PubMed, CAS, Scopus and Google Scholar

- Research which is freely available for redistribution 